\title{
The use of a concrete additive to eliminate returned concrete waste volumes
}

\author{
Johannes Bester ${ }^{1, *}$, Deon Kruger $^{2}$, and Broadley Miller $^{3}$ \\ ${ }^{1}$ University of Johannesburg, PO Box 524, Auckland Park, 2006, Johannesburg, South \\ Africa ${ }^{2}$ University of Johannesburg, PO Box 524, Auckland Park, 2006, Johannesburg, South Africa \\ ${ }^{3}$ University of Johannesburg, PO Box 524, Auckland Park, 2006, Johannesburg, South Africa
}

\begin{abstract}
This paper investigates the effects of the use of a recently developed two-component powdered product made from polymers and inorganic compounds that can be mechanically mixed into returned fresh ready-mix concrete to allow for the separation of the concrete into fine and coarse aggregates. This allows for the re-use of the returned concrete as aggregates in the manufacturing of new concrete. The returned concrete waste can therefore be eliminated, thus reducing virgin aggregate usage, as well as reducing the environmental impact of returned concrete. In this study, the treated recycled fresh concrete was separated into fine and coarse aggregates, and then used at replacement levels of $0 \%, 25 \%, 50 \%, 75 \%$ and $100 \%$. The effect of the product on the material classification, and on important fresh and hardened properties of the concrete for the abovementioned replacement values was tested. For the fine aggregate, the results indicate minimal changes in both the fresh and hardened properties. For the coarse aggregate, the results show a marked improvement of flexural strength with an increase in replacement value when coarse aggregates are used. Very high replacement levels may be used with very little effect on the quality of the new concrete.
\end{abstract}

\section{Introduction}

A study conducted by Obla et al for the RMC Research \& Education Foundation found that there are four ways in which returned concrete can be used, of which one way is to discharge the concrete at the concrete plant, allow the concrete to harden, and then crushed. The crushed material can then be used as fill or as base for pavements. The report further states that the fines proofs to be a significant challenge for the producer to dispose off [1]. This leaves the question whether returned concrete, in the fresh state, could be utilized, rather than allowing the returned concrete to harden.

Returned concrete from construction sites have for long been a problem in South Africa (SA). This product have typically been send of to landfill sites, or has been treated in settling ponds. Both of these methods are not environmentally desirable. In addition, these methods are not cost effective, and are in conflict with municipal environmental regulations [2]. The

\footnotetext{
*Corresponding author: jannesb@uj.ac.za
} 
triple bottom line theory of sustainable development consists of three parts, namely enonomic, environment- and social factors, as shown in Figure 1 [3]. It is important that a balance is achieved between these three factors, to achieve an increase in sustainability. This having been said, any small contribution from any of these factors will have an effect on sustainability.

A new two-component powdered product made from special polymers and inorganic compounds has entered the market in South Africa (SA). This product allows concrete returned to mixing plants, at the end of the day, to be completely and quickly recovered directly from truck mixers. The product, when added to concrete whilst still in its plastic state, first absorbs the water in the concrete mix and rapidly sets it, to transform the concrete into a granular material with excellent mechanical characteristics which, may be used to partially replace natural aggregates.

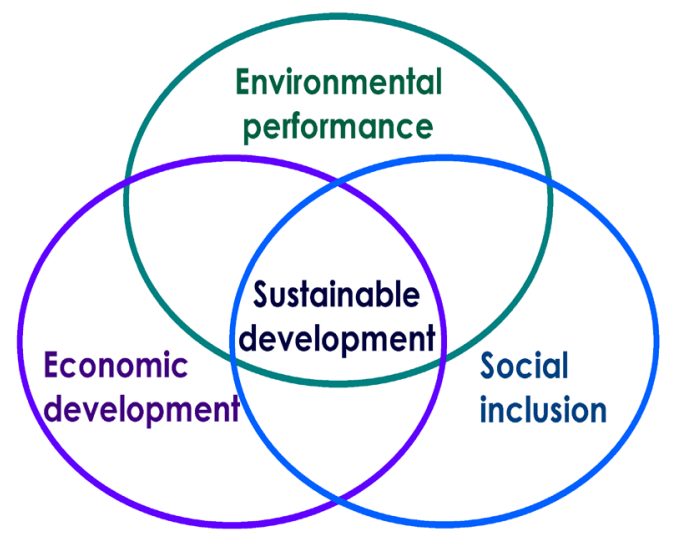

Fig. 1. Triple bottom line [4].

Returned concrete (Ret. Con.) is the unused portion left over in the ready-mix truck after delivery and use by the client. This material, when still in the fresh concrete state, is currently not being utilized by most ready-mix concrete suppliers and causes major waste streams for proper disposal of large amounts of water used to wash out the agitator and aggregate that is merely landfilled or used as fill or base material. The water after washing needs to be properly processed to remove the hazardous components before it can be discharged from the site. This waste stream therefor has great potential to reduce operating costs of ready-mix suppliers if the material could be more efficiently utilised as well as offering them the opportunity to reduce their environmental impact on the surrounding environment.

The objective of this research project is to prove that returned concrete, a common wasted material, can be successfully recycled to be used in concrete to replace or partially substitute the virgin aggregate needed in the production of new concrete, thus reducing the need for as much virgin material and also reducing the waste stream destined for landfilling by finding an alternate use for the waste stream generated in the construction industry.

\section{Experimental design}

The aggregate was produced from the treatment of returned concrete from a ready-mix vehicle, to test the effects of its use as specified by the manufacturer. After treatment and discharge of the material from the ready-mix vehicle, the aggregate was air-dried until use as aggregate replacement in the test concrete mixes. 
A control mix is designed and made using the procedure set out in the Fulton's Concrete Technology handbook, [5], using a specified slump, water-cement ratio and readily available crushed stone and sand aggregate used in typical ready-mix concretes mixes supplied by the Afrisam Roodepoort Plant. The control strength aimed for, and achieved, was $20 \mathrm{MPa}$.

\section{Results}

\subsection{Fresh properties}

\subsubsection{Slump values}

The slump values of the treated returned concrete, where the sand portion was used in the new mixes, for all the sand replacement values remained mainly unchanged when compared to the control mix, as can be seen in Figure 2. This could be that the properties of the more round shape of the particles counteract the higher water absorption rates expected from the returned concrete aggregates. The same was observed for the stone portion, as can be seen in Figure 3.

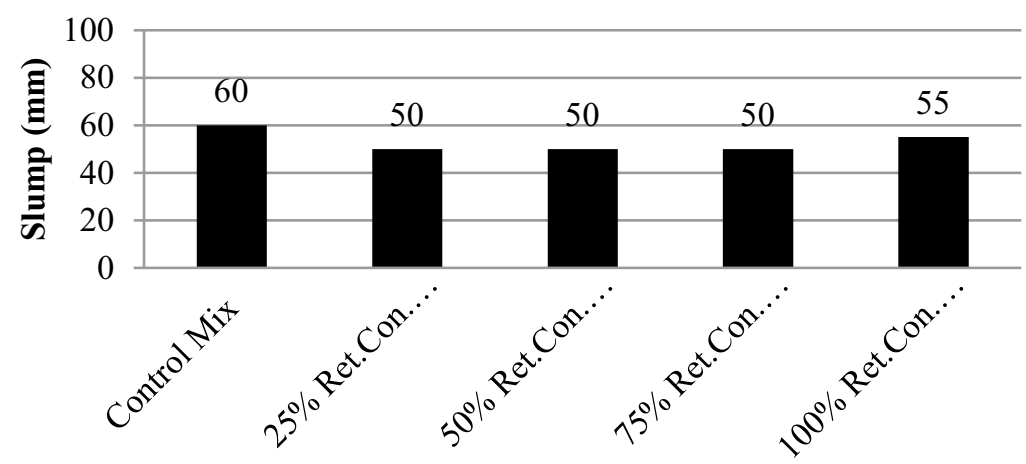

Fig. 2. Slump values for the returned concrete sand aggregate concrete.

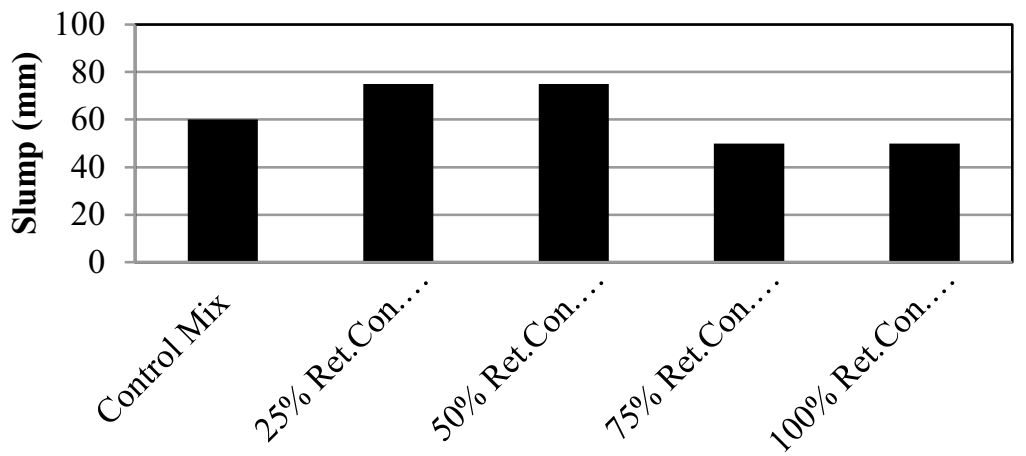

Fig. 3. Slump values for the returned concrete stone aggregate concrete.

This was surprising, as the manufacturer of the product stated that concrete mixes containing the recycled material as aggregate at a 50\% replacement level would require 
around $10 \ell$ per $1 \mathrm{~m}^{3}$ concrete to yield the same workability as a concrete mix containing only virgin aggregates, yet the workability slightly increased at a $50 \%$ replacement with the same water content.

\title{
3.1.2 Slump retention
}

The slump retention results of the mixes containing both the returned concrete sand and stone material, shown in Figure 4 and Figure 5, had much the same slopes as that of the reference mix. This again was interesting as the material was expected to have higher water absorption from the lower relative density than that of the reference material, which should have caused a reduction in the slump retention experienced. Therefore, as with returned concrete sand and stone material, it can be assumed that the use of the returned concrete sand material as aggregate in concrete would have little effect on the slump retention properties of the concrete made therewith.

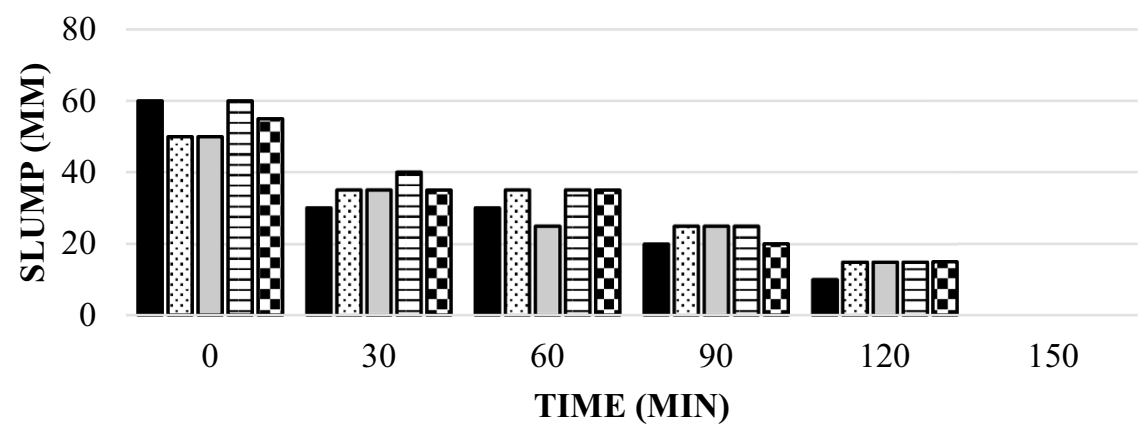

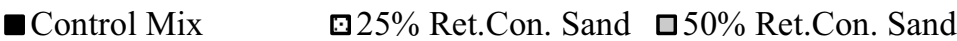 \\ 日75\% Ret.Con. Sand $\quad \mathbf{1 0 0 \%}$ Ret.Con. Sand
}

Fig. 4. Slump retention for the returned concrete sand aggregate concrete.

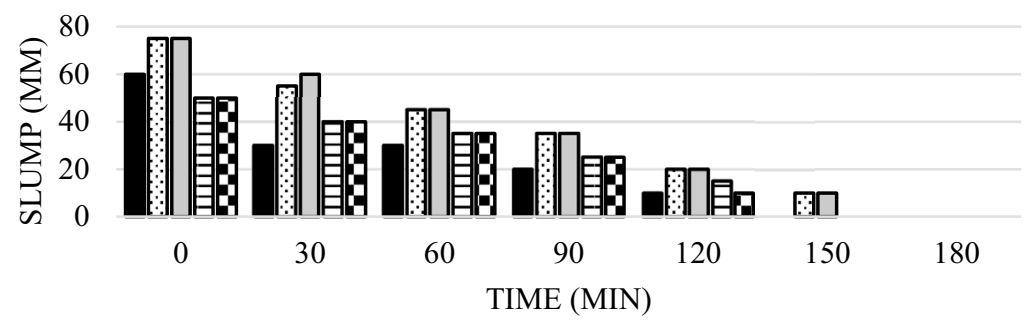
- Control Mix
๑25\% Ret.Con. Stone $\square 50 \%$ Ret.Con. Stone
口75\% Ret.Con. Stone
口 $100 \%$ Ret.Con. Stone

Fig. 5. Slump retention results for the returned concrete stone aggregate concrete.

\subsubsection{Setting time}

The returned concrete stone material setting time results, seen in Figure 6, showed a slight increase in the setting times at the $25 \%$ replacement mix and thereafter a trend of decreasing 
setting times as the replacement value increased. The setting times of the $50 \%$ replacement concrete however could be presumed to be a slight outlier as the setting times achieved by this mix is slightly lower than expected if the trend is to be believed. The setting times of the returned concrete sand material (Figure 7), showed a marked reduction in the setting times achieved by the mixes containing the returned concrete sand material compared to that of the control material. What was interesting to note was that, although the initial setting time showed a trend of reduced set setting times as the level of replacement increased, the final set time seemed to remain unaffected by the level of replacement. This was unexpected as the material was thought to have a large degree of un-hydrated cement particles present that should have caused the setting phase time to decrease.

The reduction in the initial setting times is presumed to be as a result of the higher water absorption properties of the returned concrete sand material taking water out of the concrete mix, effectively reducing the workability, however, this seems to conflict with the slump retention results shown earlier, that revealed that the concretes containing the returned concrete sand material as aggregate had much the same slump retention properties as that of the control mix.

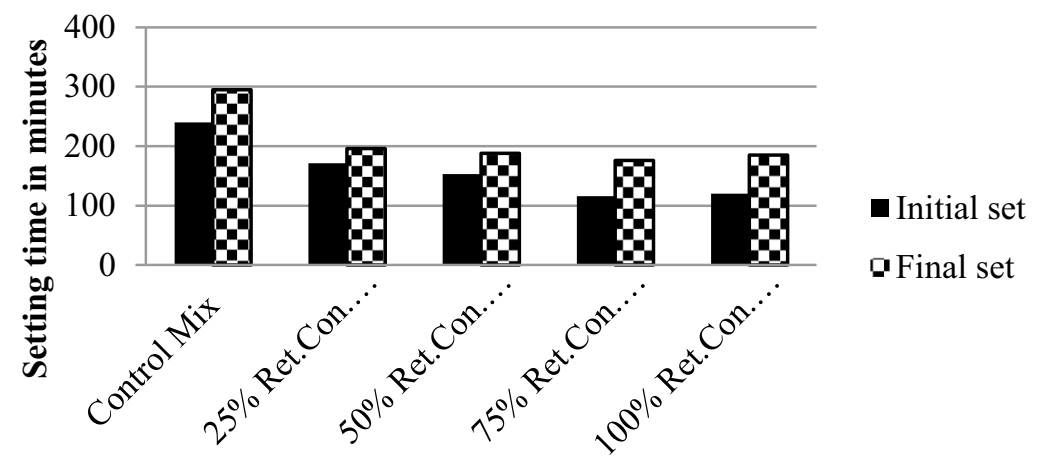

Fig. 6. Setting time results for the returned concrete sand aggregate concrete.

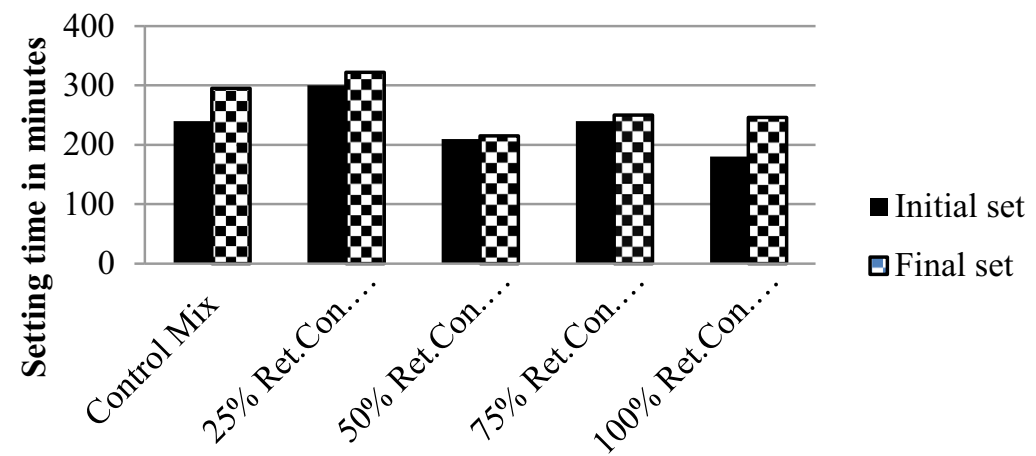

Fig. 7. Setting time results for the returned concrete stone aggregate concrete.

\subsubsection{Bleeding}

It is important to note that the bleed volume results in this study were only the bleed volumes measured on the surface of the concrete after the 280 minute test period, and not the total bleed volume of the concrete. This is because weight measurements of the test samples after 
being oven-dried were not done and therefore, the total bleed volumes could not be calculated.

The bleed volumes achieved by the concrete mixes containing the returned concrete stone material, shown in Figure 8, yielded much lower bleed volumes than that of the reference mix. The mixes also show a slight trend toward lower bleed volumes as the level of replacement increased. The reason expected for this large difference in bleed volumes experienced is due to the higher water absorption of the material absorbing free water in the mix.

The concrete sand material, Figure 9, had an even larger effect on the bleeding than that of the returned concrete stone material which was unexpected as the lower amount of very

fine particles present in the returned concrete sand material compared with that of the

reference material was expected to increase the bleeding experienced. However, it is believed that the recycled material's higher absorption caused it to absorb the bleed water from the mix, thus effectively reducing the bleed amounts on the surface of the concretes.

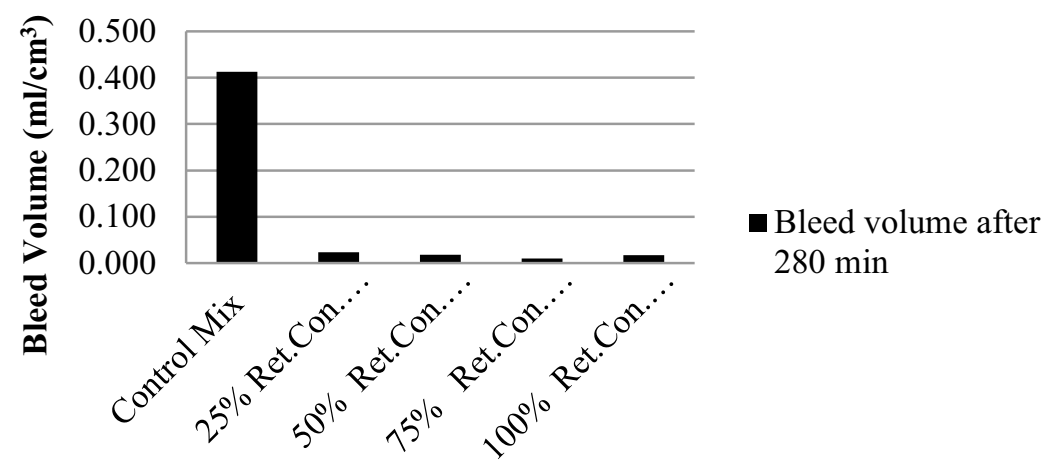

Fig. 8. Bleed volume results for the returned concrete sand aggregate concrete.

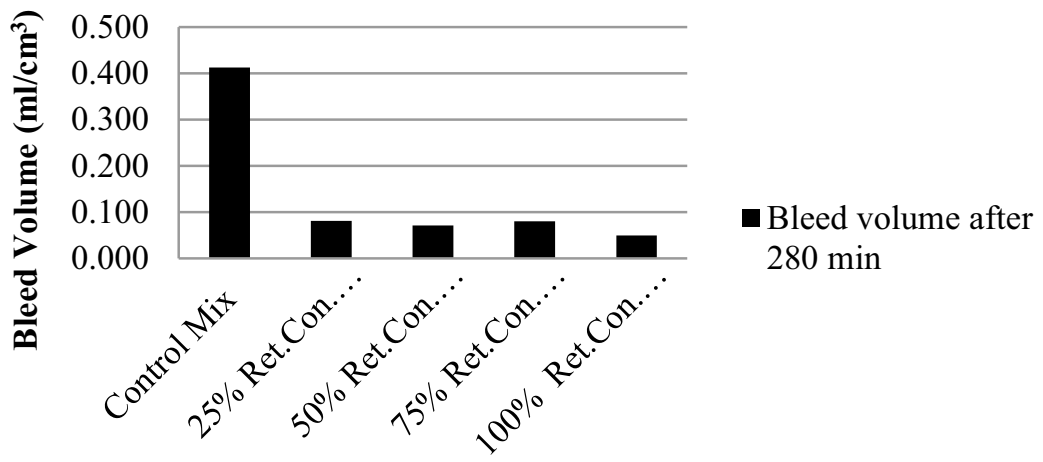

Fig. 9. Bleed volume results for the returned concrete stone aggregate concrete.

\subsubsection{Compressive strength}

The compressive strengths achieved by both the returned concrete sand and stone material, as shown in Figures 10 and 11, were marginally lower than that of the reference concrete, yielding less than $10 \%$ loss in compressive strength at a $25 \%$ replacement value and the material continues the trend with RCA of a decreasing compressive strength as the level of replacement increased. 
The loss in compressive strength is at odds with the manufacturer of 'Product A' claims that states although it retards the compressive strength gain initially, in that the material actually yields a marginally higher compressive strength after 28 days than that of a reference mix containing only virgin aggregates. The reason for this loss in compressive strength could be as a result of the original concrete's low compressive strength, as it was a specified 20 $\mathrm{MPa}$ concrete, as stated earlier. This lower strength original concrete could have caused the attached cement mortar present on the returned concrete stone material to be of a lower strength, thus negatively affecting the strength capabilities if the concretes made therewith.

The concrete's loss in strength seemed to be much less reactive to the increase in the level of replacement, than that of the lab waste RCA and almost seems at odds with the manufacturer's recommendations not allowing replacement values of more than $50 \%$.

Although the compressive strength of the concretes decreased with the replacement of virgin aggregate with that of the returned material, the reduction in compressive strengths achieved at low levels of replacement is quite small, i.e. $25 \%$ replacement having a loss of less than $10 \%$ of its compressive strength.

The almost perfect distribution of results could also be an indication that the material is consistent in its properties. Therefore, it is expected that the effects of the lab waste material on concretes made therewith, can be controlled and therefor mitigated with proper design considerations.

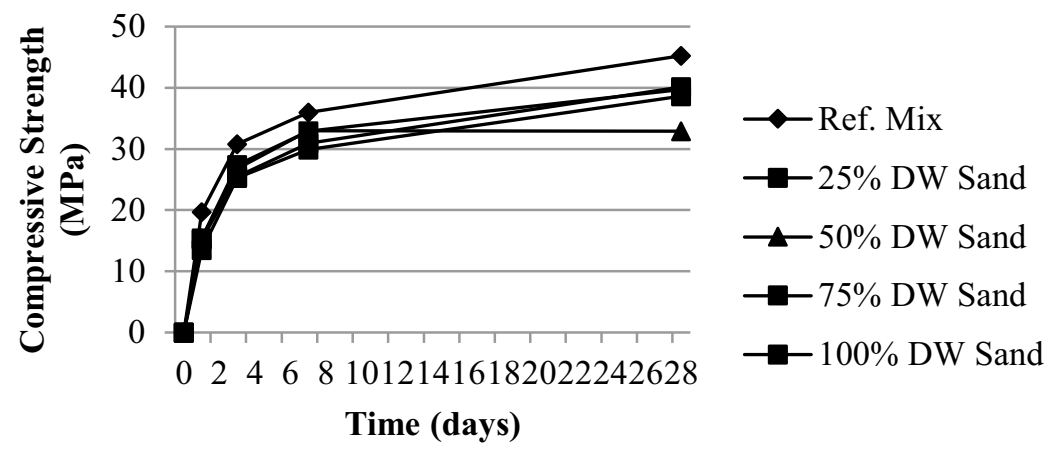

Fig. 10. Compressive strength results for the returned concrete sand aggregate concrete.

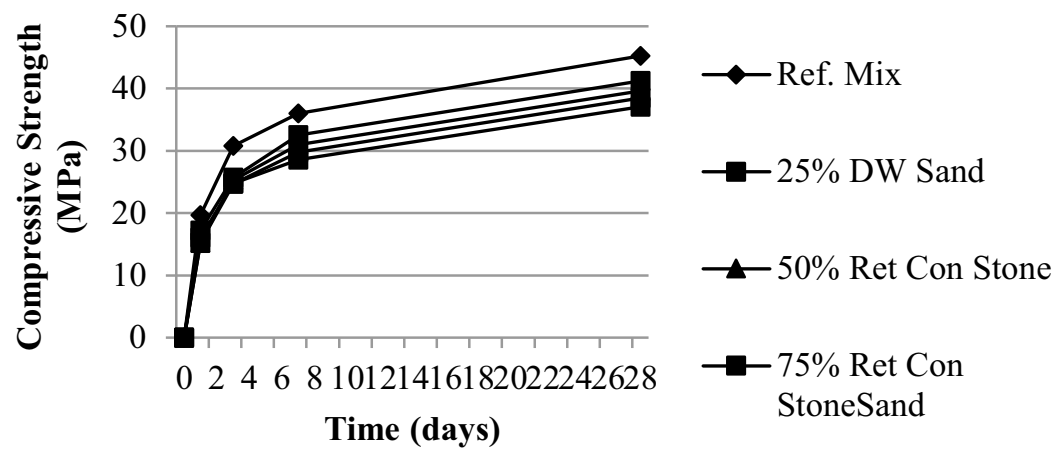

Fig. 11. Compressive strength results for the returned concrete stone aggregate concrete. 


\subsubsection{Flexural strength}

The flexural strengths achieved by the returned concrete stone material, shown in Figure 12, impressed the most, consistently outperforming the reference mix at any replacement level. The returned concrete stone material again showed a trend of decreasing flexural strengths achieved as the level of replacement increased, as expected when the compressive strengths achieved are taken into account.

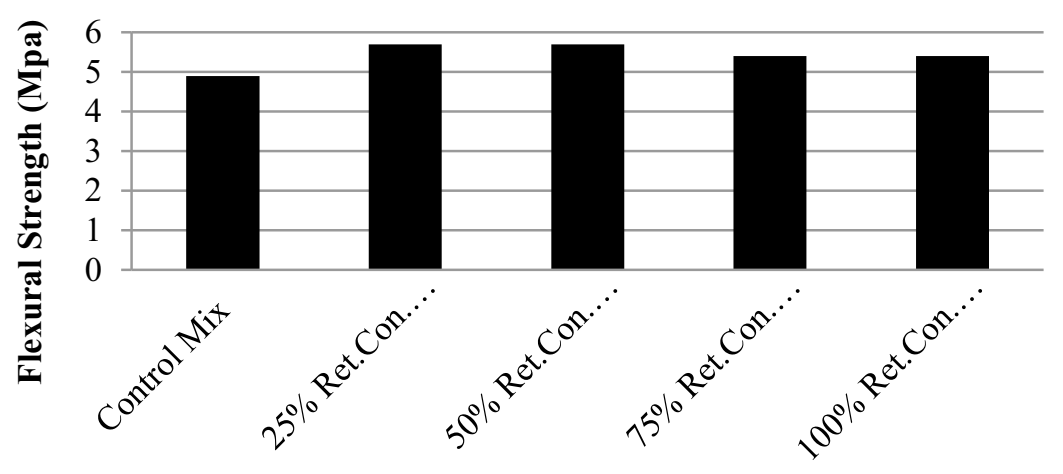

Fig. 12. Flexural strength results for the returned concrete stone aggregate concrete.

The reference concrete achieved a flexural strength to compressive strength ratio of around 1:10, as expected from most concretes containing virgin aggregates in SA. However, the mixes containing the returned concrete stone RCA's yielded ratios of around 1.4:10. This higher flexural strength is due to the improved interfacial bond strength between the aggregate and the cement mortar paste, caused by the rougher texture of the RCA compared with that of the virgin aggregate.

The flexural strength results achieved by the returned concrete sand material, shown in Figure 13, were marginally lower than that of the reference concrete and surprisingly showed a trend of increasing flexural strengths as the level of replacement increased, possibly caused by the better interfacial bond strength of the recycled aggregates to the new cement mortar due to the rougher texture.

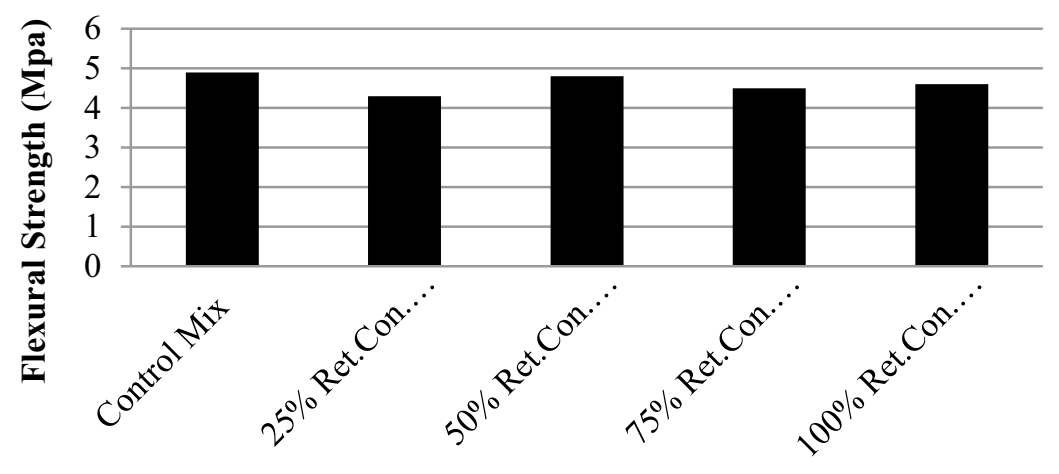

Fig. 13. Flexural strength results for the returned concrete sand aggregate concrete.

The 50\% replacement mix again tested better than expected, as with the compressive strengths showed earlier, yielding a higher flexural strength than the other replacement levels. However, when compared with the trend produced by the other mixes this much higher value could be considered as an outlier. 
The ratios of flexural strength to compressive strength tested almost exactly the same as the reference mix with values around 1.1:10 and the 100\% replacement level concrete achieving the best result at almost 1.2:10. This means that the returned concrete sand material reacts in much the same way as the reference aggregate and thus would not adversely affect the concrete flexural properties if it were used as aggregate.

\section{Conclusions}

From the results obtained in this research project, it can be seen that the slump for both the sand and stone replacement, at any replacement values, was not affected. The slump retention was also largely not affected. The initial set and final set was shorter than for the control mix. There is a massive reduction in the bleed volume for both the sand and stone replacement mixes, at all the replacement values. This could cause the fresh concrete to undergo plastic shrinkage cracking, and should be taken into consideration in the mix design, as well as in site practice.

In addition, the hardened properties of the concrete when the returned concrete was used, showed a slight decrease when both the stone and sand fraction was used. This is evident in all the replacement values. When the flexural strength is considered, there is an increase in the flexural strength of the concrete that was made using the stone fraction of the treated concrete, but a very slight decrease in the sand fraction.

The results from this study indicates that the two-component powdered product may be used on returned concrete, in order to allow the returned concrete to be used in new concrete, with minimal changes to the mix design.

\section{References}

1. K. Abla, H. Kim, C. Lobo, Crushed returned concrete as aggregates for new concrete. Final report to the RMC Research \& Education Foundation. Project 05-13. (2007)

2. http://www.leadingarchitecture.co.za/recover-returned-concrete-within-minutes. Date accessed: 2016/12/07.

3. G. Owens, (Editor). Fundamentals of Concrete. Midrand. The Concrete Institute, pp.8. (2013).

4. http://www.theconcreteinstitute.org.za/in-perspective. Date accessed: 2016/12/15.

5. B. Addis, J. Goodman. Concrete mix design. Chapter 11 in Fulton's concrete technology. Midrand: The Cement \& Concrete Institute, pp. 219-224. 